\title{
Association of IL-1 $\beta$ and IL-1 receptor antagonist haplotypes with rate of decline in lung function in smokers
}

L Joos, L McIntyre, J Ruan, J E Connett, N R Anthonisen, T D Weir, P D Paré, A J Sandford

\begin{abstract}
Background-There is increasing evidence that the cytokine network is central to the immunopathology of inflammatory airway diseases. The interleukin 1 (IL-1) receptor antagonist (IL-1RN) is a naturally occurring anti-inflammatory agent that binds to the IL-1 receptor but does not possess agonist activity. Each of the genes of the IL-1 locus on chromosome $2 q 14$ is polymorphic. The IL1RN gene contains an $86 \mathrm{bp}$ tandem repeat and allele 2 of this polymorphism has been associated with various inflammatory diseases. The IL-1ß (IL1B) gene contains a promoter polymorphism (C-511T) that has been associated with inflammatory diseases and is in linkage disequilibrium with the ILIRN polymorphism.
\end{abstract}

Methods-We investigated whether polymorphisms in the IL1B and IL1RN genes were associated with rate of decline of lung function. Genotypes were determined in 284 smokers with a rapid decline in lung function and 306 smokers with no decline in lung function.

Results-None of the genotypes was associated with the rate of decline of lung function. However, the distribution of ILIBIIL1RN haplotypes was different between smokers with a rapid decline in lung function and those with no decline in lung function $(p=0.0005)$.

Conclusion-These results suggest that ILIBIIL1RN haplotypes play a role in the rate of decline in lung function in smokers.

(Thorax 2001;56:863-866)

Keywords: interleukin 1; lung function; smoking; polymorphism (genetics)

Biostatistics, School of

Public Health,

University of

Minnesota, USA

J E Connett

Faculty of Medicine, University of

Manitoba, Canada

N R Anthonisen

Correspondence to: Dr A J Sandford asandford@mrl.ubc.ca

Received 6 September 2000 Returned to authors

8 November 2000

Revised version received

31 May 2001

Accepted for publication

18 June 2001 Interleukin 1 (IL-1) and similar cytokines play a central role in chronic inflammatory diseases. ${ }^{1}$ The IL-1 family consists of two pro-inflammatory cytokines, IL- $1 \alpha$ and IL- $1 \beta$, and a naturally occurring anti-inflammatory agent, the IL-1 receptor antagonist (IL-1RN). The two forms of IL-1 are the products of different genes, but they are structurally related and bind to the same receptor. They are synthesised by a variety of cell types, mainly monocytes and macrophages. IL-1RN is a $16-18 \mathrm{kD}$ protein that binds to the IL-1 receptor with the same affinity as IL-1 but does not possess agonist activity and therefore acts as a competitive inhibitor of IL-1. ${ }^{2}$ IL-1 and its antagonist may influence the rate of decline in lung function because of the effects of IL- 1 on neutrophil function and chemotaxis. IL-1 stimulates the synthesis of IL-8 which is a potent chemotactic agent for neutrophils and it also induces release of neutrophil elastase. ${ }^{3}$ IL-1 promotes the adhesion of neutrophils and other cells by enhancing the expression of adhesion molecules such as ICAM-1, VCAM-1, and L-selectin. ${ }^{4}$

Evidence for a contribution of the IL-1 gene complex to the pathogenesis of inflammatory airway disease was provided by measurements of IL- 1 in asthmatic subjects. IL-1 $\beta$ expression in the alveolar macrophages of asthmatic subjects is upregulated ${ }^{6}$ and there is increased protein expression of both IL- $1 \beta$ and IL- $1 \mathrm{RN}$ in biopsy specimens of the bronchial epithelium of asthmatics. ${ }^{7}$ In animal models, intratracheal administration of IL-1 $\beta$ to BrownNorway rats leads to an increased number of neutrophils in bronchoalveolar lavage fluid and increased airway hyperresponsiveness to bradykinin. ${ }^{8}$ Pretreatment with IL-1RN reduces bronchial hyperreactivity in guinea pigs. ${ }^{9}$

The genes of the IL-1 complex map to the long arm of chromosome $2,{ }^{10}$ and each of the genes is polymorphic. The IL-1 $\beta$ gene (IL1B) has a single nucleotide polymorphism in the promoter region $(\mathrm{C}-511 \mathrm{~T})^{11}$ and the IL1RN gene has a penta-allelic polymorphic site in intron 2 containing 2-6 tandem repeats of an $86 \mathrm{bp}$ sequence. ${ }^{12}$ There is evidence that allele 2 of the IL1RN gene (IL1RN`2) is associated with increased susceptibility or more severe outcome in chronic inflammatory diseases such as ulcerative colitis, systemic lupus erythematosus, and alopecia areata. ${ }^{13-17}$ The IL1B C-511T has been associated with inflammatory bowel disease ${ }^{18}$ as well as plasma levels of IL- $1 \beta$ and IL-1RN. ${ }^{19}$

Chronic obstructive pulmonary disease
(COPD) is a chronic inflammatory disease that is associated with progressive airway remodelling and obstruction. The role of $I L 1 B$ and $I L 1 R N$ polymorphisms in COPD has only been investigated in a small number of subjects. ${ }^{20} I L 1 R N^{\star} 2$ has been associated with non-atopic asthma in a Japanese population, ${ }^{21}$ but not in black or white South African individuals. ${ }^{22}$ We hypothesised that carriers of $I L 1 R N^{\star} 2$ and $I L 1 B-511 \mathrm{~T}$ who smoked would have more severe airflow obstruction and a more rapid decline in lung function than smokers who did not have these alleles. 
Table 1 Characteristics of 590 participants in the Lung Health Study group divided into those with no decline and those with a rapid decline in lung function

\begin{tabular}{llll}
\hline & $\begin{array}{l}\text { No decline } \\
(n=306)\end{array}$ & $\begin{array}{l}\text { Rapid decline } \\
(n=284)\end{array}$ & p value \\
\hline Age & $47.6(0.4)$ & $49.6(0.4)$ & 0.0004 \\
Sex (\% men) & $67 \%$ & $58 \%$ & 0.04 \\
Rate of decline (ml/year) & $14.9(2.0)$ & $-153.6(2.1)$ & $<0.0001$ \\
Pack-years & $38.4(1.1)$ & $42.9(1.1)$ & 0.003 \\
$\begin{array}{l}\text { Baseline FEV (\% predicted) } \\
\text { Methacholine response (\%) }\end{array}$ & $75.7(0.5)$ & $72.7(0.5)$ & $<0.0001$ \\
$\quad\left(O^{\prime}\right.$ Connor slope $)$ & $-7.8(1.5)$ & $-23.0(1.5)$ & $<0.0001$ \\
\hline
\end{tabular}

Values are mean (SE).

$\mathrm{FEV}_{1}=$ forced expiratory volume in 1 second.

* Percentage decline in $\mathrm{FEV}_{1}$ per final cumulative dose of methacholine administered. ${ }^{33}$

\section{Methods}

SUBJECTS

Subjects were selected from the participants in the NHLBI Lung Health Study. The design of this multicentre randomised clinical trial is described more extensively elsewhere. ${ }^{23}$ Study participants were healthy current smokers aged 35-60 who had mild to moderate airflow obstruction (forced expiratory volume in 1 second $\left(\mathrm{FEV}_{1}\right) 55-90 \%$ of predicted). Exclusion criteria included serious illnesses such as cancer, heart attack, stroke, or other important conditions that required medical treatment. The primary outcome was rate of decline of $\mathrm{FEV}_{1}$ over a follow up period of 5 years. Of the 3216 persistent smokers in this cohort, 284 were chosen for having the most rapid decline in lung function (decline in $\mathrm{FEV}_{1}>3.0 \%$ predicted per year), and 306 were selected
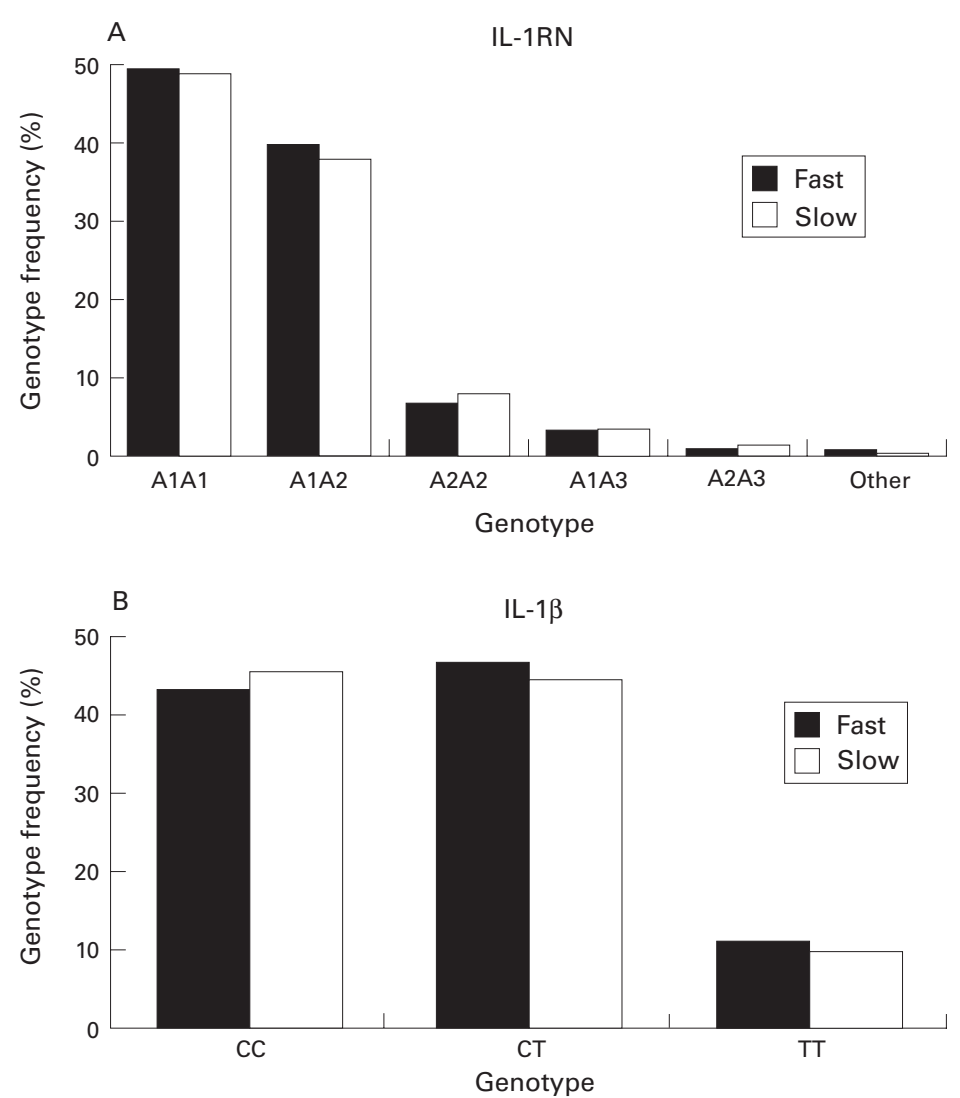

Figure 1 Frequency of IL1RN and IL1B genotypes in smokers with ( $n=284$, black bars) and without ( $n=306$, white bars) a decline in lung function over 5 years. The differences in genotype frequencies were not statistically significant. because of absence of decline over the same period (increase in $\mathrm{FEV}_{1}>0.4 \%$ predicted per year). All participants were white.

\section{GENOTYPING}

DNA was extracted from blood samples using a standard phenol/chloroform protocol. ${ }^{24}$ The promoter region of $I L 1 B$ contains a single nucleotide repeat at position $-511(\mathrm{C} \rightarrow \mathrm{T})$. The following primers flanking this region were used to amplify the polymorphic region by PCR: 5' TGG CAT TGA TCT GGT TCA TC (sense) and 5' GTT TAG GAA TCT TCC CAC TT (antisense). ${ }^{11}$ The 306 bp polymerase chain reaction (PCR) product contains a cut site for DdeI resulting in two fragments of 146 and $160 \mathrm{bp}$, respectively. The $\mathrm{C}$ allele contains an additional cut site resulting in three fragments of 160, 114 and $32 \mathrm{bp}$, respectively. Polymerase chain reaction conditions were as follows: 40 cycles at $94^{\circ} \mathrm{C}$ for 30 seconds, $57^{\circ} \mathrm{C}$ for 30 seconds, and $72^{\circ} \mathrm{C}$ for 20 seconds.

Intron 2 of the IL-1RA gene contains a variable number of tandem repeats of an $86 \mathrm{bp}$ length of DNA. The following primers flanking this region were used to amplify the polymorphic region by PCR: 5' CTC AGC AAC ACT CCT AT (sense) and 3' TCC TGG TCT GCA GGT AA (antisense). ${ }^{12}$ Polymerase chain reaction conditions were as follows: 35 cycles at $94^{\circ} \mathrm{C}$ for 30 seconds, $60^{\circ} \mathrm{C}$ for 30 seconds, and $72^{\circ} \mathrm{C}$ for 20 seconds.

The size of the amplified products was determined by electrophoresis on a $2 \%$ agarose gel stained with ethidium bromide for visualisation with ultraviolet light. Negative controls without DNA template were included with each reaction. All analyses were performed blind with respect to subject characteristics. Genotypes were confirmed by a second person not directly involved in the study.

\section{STATISTICAL ANALYSIS}

The results are presented as genotype and allele frequencies for both subjects with a rapid decline in lung function and those with no decline in lung function among the participants in the Lung Health Study. $\chi^{2}$ tests for statistical significance were performed on allele frequencies. Logistic regression was used to adjust the results for potentially confounding variables such as age, sex, cigarette smoking, baseline lung function, and response to methacholine. Unpaired $t$ tests were used to compare baseline values. Haplotype frequencies and linkage disequilibrium were estimated using the expectation-maximisation (EM) algorithm implemented in the Arlequin software package. ${ }^{25}$

\section{Results}

The characteristics of the 590 smokers are given in table 1. Figure 1A shows the distribution of ILIRN genotypes within the groups of smokers who had a rapid decline and those with no decline in lung function. The observed genotype frequencies were similar to those previously reported. ${ }^{12}$ Figure 1B shows the distribution of $I L 1 B$ genotypes in the smokers who had a rapid decline and those who had no 
Table 2 Frequency of ILIRN/IL1B haplotypes in the study groups estimated using the expectation-maximisation (EM) algorithm ${ }^{2}$

\begin{tabular}{lllll}
\hline Haplotype & $\begin{array}{l}\text { Fast decline } \\
(n=545)\end{array}$ & $\begin{array}{l}\text { No decline } \\
(n=582)\end{array}$ & $\begin{array}{l}\text { Odds ratio for fast } \\
\text { decline }(95 \% \text { CI })\end{array}$ & $\begin{array}{l}\text { p value (fast v no } \\
\text { decline) }\end{array}$ \\
\hline IL1RN A1/IL1B -511C & 0.51 & 0.55 & $0.8(0.7$ to 1.1$)$ & 0.0005 \\
IL1RN A2/IL1B -511C & 0.14 & 0.10 & $1.4(1.0$ to 2.1$)$ & \\
IL1RN A3/IL1B -511C & 0.01 & 0.03 & $0.5(0.2$ to 1.2$)$ & \\
IL1RN A1/IL1B -511T & 0.20 & 0.14 & $1.5(1.1$ to 2.1) & \\
IL1RN A2/IL1B -511T & 0.14 & 0.18 & $0.7(0.5$ to 0.9) & \\
IL1RN A3/IL1B -511T & 0.01 & 0 & $6.5(0.8$ to 53.9) & \\
\hline
\end{tabular}

Table 3 Linkage disequilibrium between the IL1RN and the IL1B polymorphisms

\begin{tabular}{lllll}
\hline IL1RN allele & IL1B allele & $D^{\prime *}$ & $\chi^{2}$ & pvalue \\
\hline A1 & $\mathrm{C}$ & 0.31 & 95.8 & $<0.0001$ \\
A2 & T & 0.36 & 111.2 & $<0.0001$ \\
A3 & $\mathrm{C}$ & 0.44 & 2.7 & 0.10 \\
\hline
\end{tabular}

${ }^{\star} \mathrm{D}^{\prime}$ is a measure of the extent of linkage disequilibrium, expressed as a percentage of its maximal value given the allele frequencies in the population $\left(\mathrm{D}^{\prime}=\mathrm{D} / \mathrm{Dmax}\right) .{ }^{34}$

decline in lung function. For both polymorphisms the overall observed distribution of homozygotes and heterozygotes conformed to expectations based on Hardy-Weinberg analysis.

Carriers of the $I L 1 B-511 \mathrm{~T}$ or the $I L 1 R N^{\star} 2$ allele were not more frequent in the group who had a rapid decline in lung function, even after adjusting for the significantly different baseline values (age, sex, pack-years, baseline $\mathrm{FEV}_{1} \%$ predicted, response to methacholine). However, there was a significant difference in $I L 1 B$ IL1RN haplotype distribution between those with a rapid decline in lung function and those in whom there was no decline (table 2). Of the individual haplotypes, IL1RN A1/IL1B -511T was increased in those whose lung function declined rapidly (odds ratio (OR) $1.5,95 \%$ CI 1.1 to $2.1, \mathrm{p}=0.01$ ) and IL1RN A2/IL1B $-511 T$ was significantly decreased in this group (OR $0.7,95 \%$ CI 0.5 to $0.9, p=0.02)$. As in previous studies, ${ }^{26}$ linkage disequilibrium was found between IL1RN VNTR and the ILIB polymorphism (table 3).

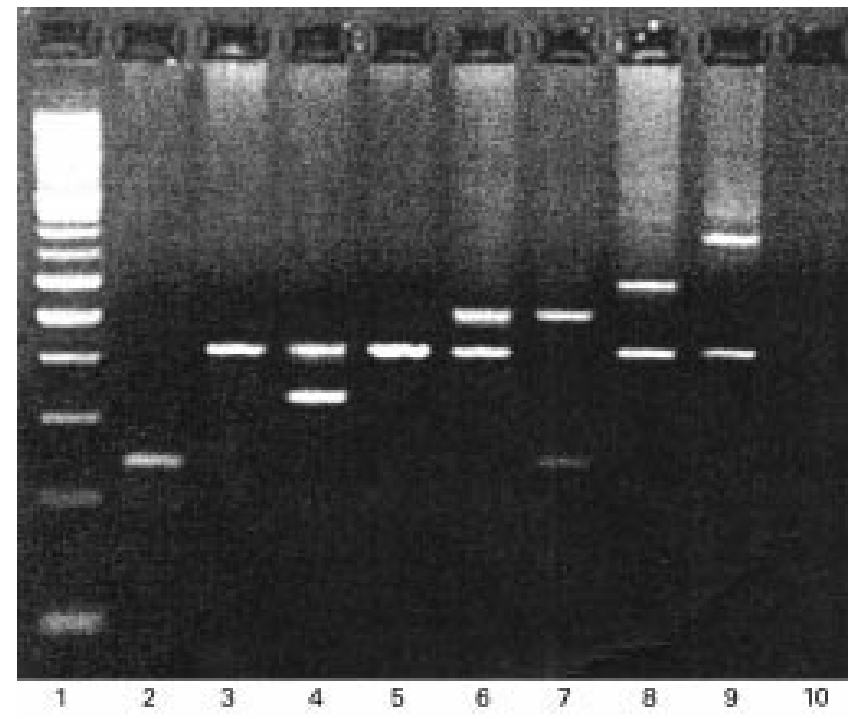

Figure 2 Two per cent agarose gel displaying IL1RN genotypes. Lane 1: 100 bp DNA ladder; lane 2: allele 2 homozygote (240 bp, 2 repeats); lanes 3 and 5: allele 1 homozygote (412 bp, 4 repeats); lane 4: allele 4 heterozygote (326 bp, 3 repeats); lanes 6 and 7: allele 3 heterozygote (498 bp, 5 repeats); lane 8: allele 5 heterozygote (584 bp, 6 repeats); lane 9: allele 6 heterozygote (756 bp, 8 repeats); lane 10: negative control.
Five alleles of the IL1RN gene have been previously described. ${ }^{12}$ We found a sixth allele that consisted of eight repeats of the $86 \mathrm{bp}$ sequence (fig 2 ).

\section{Discussion}

We have investigated polymorphisms in the IL-1 gene cluster as risk factors for accelerated decline in lung function. Genotype frequencies were compared in smokers with a rapid decline in lung function and those with no decline in lung function. There was a strong association between IL1RN/IL1B haplotypes and decline in lung function. Allele 1 of the ILIRN gene in combination with the $I L 1 B \mathrm{~T}$ allele was a risk factor for an accelerated rate of decline in lung function. In contrast, allele 2 of the IL1RN gene in combination with the IL1B T allele was protective against a rapid decline in lung function.

$I L 1 B$ and $I L 1 R N$ are logical candidate genes in inflammatory airway diseases because of the critical role of IL-1 in inflammation. The actions of IL-1 include activation of T and B cells, and chemotaxis of neutrophils and macrophages. In addition, IL-1 stimulates the production of other cytokines such as tumour necrosis factor (TNF) and granulocytemacrophage colony stimulating factor (GM$\mathrm{CSF}) .{ }^{1}$ Airway inflammation is a common feature in the development of both COPD and asthma. Previous studies have shown an association between $I L 1 R N^{\star} 2$ and several inflammatory and autoimmune diseases such as ulcerative colitis, systemic lupus erythematosus, diabetic nephropathy, and alopecia areata. ${ }^{13-17}$ Another polymorphism in the $I L 1 R N$ gene, which is in complete linkage disequilibrium with $I L 1 R N^{\star} 2$, has been associated with fibrosing alveolitis. ${ }^{27}$ The $I L 1 B$ C-511T polymorphism has been associated with several diseases including inflammatory bowel disease, ${ }^{18}$ alcoholic cirrhosis, ${ }^{28}$ and Parkinson's disease. ${ }^{29}$

The functional effect of these polymorphisms remains unclear. Data on the effect of $I L 1 R N^{\star} 2$ on plasma levels of IL-1RN are contradictory. ${ }^{30}{ }^{31}$ Hurme et al investigated the effect of $I L 1 R N^{\star} 2$ in combination with the IL1B C-511T polymorphism and found that $I L 1 R N^{\star} 2$ was associated with higher plasma levels of IL-1RN than $I L 1 R N^{\star} 1$, but only in individuals who also had the T allele of $I L 1 B .{ }^{19}$ These data would appear to conflict with the reported association of the $I L 1 R N^{\star} 2$ allele with inflammatory diseases since increased production of IL-1RN would be expected to reduce the binding of IL-1 to its receptor and therefore have an anti-inflammatory effect. However, mononuclear cells from carriers of the $I L 1 R N^{\star} 2$ allele were shown to produce a higher level of IL- $1 \beta$ in vitro. ${ }^{32}$ It is possible that $I L 1 R N^{\star} 2$ predominantly increases the level of IL- $1 \beta$ and therefore leads to an imbalance in the IL-1 $\beta / \mathrm{IL}-1 \mathrm{RN}$ ratio resulting in an increased susceptibility or more severe outcome of inflammatory diseases. Alternatively, it could be hypothesised that the IL1RN`2 allele is a marker for a linked disease associated locus and may not be a direct disease causing allele. 
We found no association of either the IL-1RN or IL- $1 \beta$ genotypes with the rate of decline in lung function. However, the association of haplotypes strongly suggests that the combination of risk alleles contributes to the susceptibility to the deleterious effects of cigarette smoke on lung function. This is consistent with the in vitro data of Hurme et al. ${ }^{19}$ $I L 1 R N^{\star} 2$ in the presence of the IL1B T allele was associated with higher levels of IL-1RN in vitro and with a normal rate of decline in lung function in this study. Conversely, $I L 1 R N^{\star} 1$ in combination with the $I L 1 B$ T allele was associated with lower levels of IL-1RN in vitro and with an accelerated rate of decline in lung function. Individuals with lower levels of IL-1RN may therefore be less protected against the pro-inflammatory effects of IL-1 and thus may be more susceptible to cigarette smoke induced lung injury.

In summary, although the individual polymorphisms in the IL-1 genes were not associated with rate of decline in lung function in smokers, we were able to demonstrate a significant influence of IL1RN/ILIB haplotypes in these individuals. As in previous functional studies, this suggests that it is the combination of alleles which is important in the regulation of $I L 1 R N$ gene expression.

This study was supported by a grant from the Canadian Institutes of Health Research. The Lung Health Study was supported by contract N01-HR-46002 from the Division of Lung Diseases of the National Heart, Lung, and Blood Institute. Dr L Joos was supported by the Swiss National Science Found oos was supported by the Swiss National Science Foundation, the Swiss Society of Pneumology. Dr Sandford was supported by a Parker B Francis Fellowship.

1 Dinarello CA, Wolff SM. The role of interleukin-1 in disease. N Engl f Med 1993;328:106-13.

2 Arend WP, Malyak M, Guthridge CJ, et al. Interleukin-1 receptor antagonist: role in biology. Annu Rev Immunol receptor antagoni

3 Brandolini L, Sergi R, Caselli G, et al. Interleukin-1 beta primes interleukin-8-stimulated chemotaxis and elastase
release in human neutrophils via its type I receptor. Eur release in human neutrophils via
Cytokine Network 1997;8:173-8.

4 Abdelaziz MM, Devalia JL, Khair OA, et al. The effect of conditioned medium from cultured human bronchial epithelial cells on eosinophil and neutrophil chemotaxis and adherence in vitro. Am 7 Respir Cell Mol Biol 1995;13: 728-37.

5 Tsang YT, Neelamegham S, Hu Y, et al. Synergy between L-selectin signaling and chemotactic activation during neutrophil adhesion and transmigration. F Immunol 1997; 159:4566-77

6 Pujol JL, Cosso B, Daures JP, et al. Interleukin-1 release by alveolar macrophages in asthmatic patients and healthy subjects. Int Arch Allergy Appl Immunol 1990;91:207-10.

7 Sousa AR, Lane SJ, Nakhosteen JA, et al. Expression of interleukin-1 $\beta$ (IL-1 $\beta$ ) and interleukin-1 receptor antagointerleukin-1 $\beta$ (IL-1 $\beta$ ) and interleukin-1 receptor antago-
nist (IL-1RA) on asthmatic bronchial epithelium. Am $\mathcal{F}$

8 Tsukagoshi H, Sakamoto T, Xu W, et al. Effect of interleukin-1 $\beta$ on airway hyperresponsiveness and inflammation in sensitized and nonsensitized Brown-Norway rats. f Allergy Clin Immunol 1994;93:464-9.

9 Watson ML, Smith D, Bourne AD, et al. Cytokines contribute to airway dysfunction in antigen-challenged guinea pigs: inhibition of airway hyperreactivity, pulmonary eosinophil accumulation, and tumor necrosis factor generation by pretreatment with an interleukin-1 receptor antagonist. Am ₹ Respir Cell Mol Biol 1993;8:365-9.

10 Steinkasserer A, Spurr NK, Cox S, et al. The human IL-1 receptor antagonist gene (IL1RN) maps to chromosome
$2 \mathrm{q} 14-\mathrm{q} 21$, in the region of the IL- $1 \alpha$ and IL- $1 \beta$ loci. Genomics 1992;13:654-7.

11 di Giovine FS, Takhsh E, Blakemore AI, et al. Single base polymorphism at -511 in the human interleukin-1 $\beta$ gene (IL1 $\beta$ ). Hum Mol Genet 1992;1:450.

12 Tarlow JK, Blakemore AI, Lennard A, et al. Polymorphism in human IL-1 receptor antagonist gene intron 2 is caused by variable numbers of an $86-\mathrm{bp}$ tandem repeat. Hum Genet 1993;91:403-4.

13 Mansfield JC, Holden H, Tarlow JK, et al. Novel genetic association between ulcerative colitis and the antiinflammatory cytokine interleukin-1 receptor antagonist. Gastroenterology 1994;106:637-42.

14 Tarlow JK, Clay FE, Cork MJ, et al. Severity of alopecia areata is associated with a polymorphism in the interleukin-1 receptor antagonist gene. F Invest Dermatol 1994;103:387-90.

15 Blakemore AI, Tarlow JK, Cork MJ, et al. Interleukin-1 receptor antagonist gene polymorphism as a disease severity factor in systemic lupus erythematosus. Arthritis Rheum 1994:37:1380-5.

16 Blakemore AI, Watson PF, Weetman AP, et al. Association of Graves' disease with an allele of the interleukin-1 receptor antagonist gene. F Clin Endocrinol Metab 1995;80:111-5.

17 Blakemore AI, Cox A, Gonzalez AM, et al. Interleukin-1 receptor antagonist allele (IL1 $\mathrm{RN}^{\star} 2$ ) associated with nephropathy in diabetes mellitus. Hum Genet 1996;97:36974 .

18 Nemetz A, Nosti-Escanilla MP, Molnar T, et al. IL1B gene polymorphisms influence the course and severity of inflammatory bowel disease. Immunogenetics 1999;49:527-31.

19 Hurme M, Santtila S. IL-1 receptor antagonist (IL-1RA) plasma levels are co-ordinately regulated by both IL-1RA and IL-1 $\beta$ genes. Eur f Immunol 1998;28:2598-602.

20 Ishii T, Matsuse T, Teramoto S, et al. Neither IL-1beta, IL-1 receptor antagonist, nor TNF-alpha polymorphisms are associated with susceptibility to COPD. Respir Med 2000;94:847-51.

21 Mao XQ, Kawai M, Yamashita T, et al. Imbalance production between interleukin-1beta (IL-1beta) and IL-1 receptor antagonist (IL-1Ra) in bronchial asthma. Biochem Biophys Res Commun 2000;276:607-12.

22 Pillay V, Gaillard MC, Halkas A, et al. Differences in the genotypes and plasma concentrations of the interleukin-1 receptor antagonist in black and white South African asthmatics and control subjects. Cytokine 2000;12:819-21.

23 Connett JE, Kusek JW, Bailey WC, et al. Design of the Lung Health Study: a randomized clinical trial of early intervention for chronic obstructive pulmonary disease. Control Clin Trials 1993;14:3-19S.

24 Sambrook J, Fritsch EF, Maniatis T. Molecular cloning. A laboratory manual. 2nd ed. Cold Spring Harbor, NY: Cold Spring Harbor Press, 1989

25 Schneider S, Roessli D, Excoiffier L. A software for population genetics data analysis. Genetics and Biometry Laboratory, University of Geneva, Switzerland. 2000.

26 Feakes R, Sawcer S, Broadley S, et al. Interleukin 1 receptor antagonist (IL-1ra) in multiple sclerosis. 7 Neuroimmunol 2000;105:96-101.

27 Whyte M, Hubbard R, Meliconi R, et al. Increased risk of fibrosing alveolitis associated with interleukin-1 receptor antagonist and tumor necrosis factor-alpha gene polymorphisms. Am f Respir Crit Care Med 2000;162:755-8.

28 Takamatsu M, Yamauchi M, Maezawa Y, et al. Genetic polymorphisms of interleukin-1beta in association with the development of alcoholic liver disease in Japanese patients. Am $\mathcal{F}$ Gastroenterol 2000;95:1305-11.

29 Nishimura M, Mizuta I, Mizuta E, et al. Influence of interleukin-1beta gene polymorphisms on age-at-onset of interleukin-1beta gene polymorphisms on age-at-onset of
sporadic Parkinson's disease. Neurosci Lett 2000;284:73-6.

30 Tountas NA, Casini-Raggi V, Yang $\mathrm{H}$, et al. Functional and ethnic association of allele 2 of the interleukin- 1 receptor antagonist gene in ulcerative colitis. Gastroenterology 1999; 117:806-13.

31 Danis VA, Millington M, Hyland VJ, et al. Cytokine production by normal human monocytes: inter-subject variation and relationship to an IL-1 receptor antagonist (IL-1Ra) gene polymorphism. Clin Exp Immunol 1995;99:303-10.

32 Santtila S, Savinainen K, Hurme M. Presence of the IL-1RA allele $2\left(\right.$ IL1RN $\left.{ }^{\star} 2\right)$ is associated with enhanced IL-1 $\beta$ production in vitro. Scand F Immunol 1998;47:195-

33 O'Connor G, Sparrow D, Taylor D, et al. Analysis of doseresponse curves to methacholine. An approach suitable for population studies. Am Rev Respir Dis 1987;136:1412-7.

34 Devlin B, Risch N, Roeder K. Disequilibrium mapping: composite likelihood for pairwise disequilibrium. Genomics 1996;36:1-16. 